\title{
Robotic mitral valve repair for all prolapse subsets using techniques identical to open valvuloplasty: Establishing the benchmark against which percutaneous interventions should be judged
}

Rakesh M. Suri, MD, DPhil, ${ }^{a}$ Harold M. Burkhart, MD, ${ }^{a}$ Richard C. Daly, MD, ${ }^{a}$ Joseph A. Dearani, MD, Soon J. Park, MD, ${ }^{\mathrm{a}}$ Thoralf M. Sundt III, MD, ${ }^{\mathrm{d}}$ Zhuo Li, MS, ${ }^{\mathrm{b}}$ Maurice Enriquez-Sarano, MD, ${ }^{\mathrm{c}}$ and Hartzell V. Schaff, MD

Objective: Recent reports have shown that robotic mitral valve repair is effective in treating posterior leaflet disease; however, comparison with trans-sternal (open) valvuloplasty for all prolapse categories has not been performed. Moreover, data from the recently published EVEREST II trial infer that adverse event rates after mitral valve repair for degenerative disease are high. We therefore compared early outcomes of robotic versus open mitral valve repair for patients with mitral valve prolapse.

Methods: Among 745 consecutive patients undergoing open or robotic mitral repair for degenerative disease, 95 propensity-matched pairs were identified. Leaflet prolapse categories were similar between groups. Complete mitral valve repair was performed using identical techniques.

Results: Median crossclamp and bypass times were longer in the robotic group but decreased significantly over time $(P<.001)$. There were no conversions to open sternotomy, repair rate and early survival were $100 \%$, dismissal mitral regurgitation grade was similar $(P=1.00)$, and all patients in the robotic group had mild or less mitral regurgitation at 1 month after repair. There were no differences in adverse events $(5 \%$ open vs $4 \%$ robotic, $P=1.00)$. Patients in the robotic group had shorter postoperative ventilation time, intensive care unit stay, and hospital stay.

Conclusions: Robotic mitral valve repair allows complete anatomic correction of all categories of leaflet prolapse using techniques identical to open approaches. Robotic repair effectively corrects mitral regurgitation, offers excellent freedom from adverse events, and facilitates rapid weaning from ventilation, translating into earlier hospital dismissal. Safety and efficacy after both open and robotic mitral valve repair are higher than recently reported in the EVEREST II trial and establish a benchmark against which nonsurgical therapies should be evaluated. (J Thorac Cardiovasc Surg 2011;142:970-9)

Current iterations of heart valve guidelines predicate early referral for mitral valve (MV) repair on the ability to offer complete anatomic correction with greater than $90 \%$ certainty accompanied by low morbidity and mortality rates. ${ }^{1}$ Large clinical series examining long-term survival and durability of MV repair for leaflet prolapse have demonstrated excellent late outcomes using standardized surgical techniques $^{2,3}$ along with reduction annuloplasty support. ${ }^{4-9}$ Despite these proven results, nascent percutaneous mitral

From the Divisions of Cardiovascular Surgery, ${ }^{\mathrm{a}}$ Biomedical Statistics and Informatics, ${ }^{b}$ and Cardiovascular Diseases, ${ }^{\text {c }}$ Mayo Clinic, Rochester, Minn; and Division of Cardiac Surgery, ${ }^{\mathrm{d}}$ Massachusetts General Hospital, Boston, Mass.

The authors had full access to the data and take responsibility for its integrity. All authors have read and agree to the manuscript as written.

Disclosures: Authors have nothing to disclose with regard to commercial support.

Read at the 91st Annual Meeting of The American Association for Thoracic Surgery, Philadelphia, Pennsylvania, May 7-11, 2011.

Received for publication May 8, 2011; revisions received June 10, 2011; accepted for publication July 19, 2011; available ahead of print Sept 12, 2011.

Address for reprints: Rakesh M. Suri, MD, DPhil, Division of Cardiovascular Surgery, Mayo Clinic, 200 First St SW, Rochester, MN 55905 (E-mail: suri. rakesh@mayo.edu).

0022-5223/\$36.00

Copyright (C) 2011 by The American Association for Thoracic Surgery

doi: $10.1016 /$ j.jtcvs.2011.07.027 technologies based on incomplete anatomic correction have emerged. ${ }^{10}$

Asymptomatic or minimally symptomatic patients may seek to avoid traditional surgical incisions when lessinvasive options are available, hoping to minimize the length of temporary postoperative disability. Cohn and colleagues, ${ }^{11}$ who pioneered several early less-invasive approaches to the MV, recently published a comprehensive update, detailing the excellent early outcomes of these procedures in the current era. ${ }^{12}$ Studies have further demonstrated that full anatomic leaflet correction and annuloplasty placement for degenerative mitral disease using small right chest incisions and robotic assistance are safe and effective for all types of degenerative mitral disease. ${ }^{13-16}$ Recent data by Mihaljevic and colleagues ${ }^{17}$ selectively examining posterior mitral leaflet robotic repair confirmed these benefits. The unresolved issue, however, is which categories of mitral prolapse can or should be repaired using small ports facilitated by robotic assistance? The question is important, because recent proponents of clip technology emulating the "edge-to edge" stitch suggest that the diminished short-term effectiveness and 

Abbreviations and Acronyms
$\mathrm{CT}=$ computed tomography
ICU $=$ intensive care unit
$\mathrm{MR}=$ mitral regurgitation
$\mathrm{MV}=$ mitral valve
TTE $=$ transthoracic echocardiography

unknown long-term consequences of the MitraClip (Abbott Laboratories, Abbott Park, Ill) might be justified by the promise of presumed improvements in safety and earlier resumption of normal activities. ${ }^{10}$ In response to the concern that these latest data may not accurately reflect contemporary outcomes of surgical mitral repair in otherwise low-risk patients, we used (1) identical, (2) standard, and (3) proven MV repair techniques to compare early safety and efficacy of trans-sternal (open) versus robot-assisted MV repair to serve as a benchmark against which less complete percutaneous maneuvers might be judged.

\section{MATERIALS AND METHODS}

A total of 747 consecutive patients underwent primary open (July 1, 2007, to January 1, 2010) or robot-assisted MV repair (da Vinci S HD Surgical System; Intuitive Surgical, Inc, Sunnyvale, Calif) (January 1, 2008, to January 1,2010). We excluded those with MV pathology due to congenital, rheumatic, or ischemic disease; active endocarditis; peripheral vascular disease; or significant coronary disease; and those undergoing concomitant cardiac surgical procedures other than atrial septal defect/patent foramen ovale closure or Maze/modified Maze procedures. Among the remaining 199 patients in the open group and 102 patients in the robotic group with mitral regurgitation (MR) due to leaflet prolapse, 95 propensity-matched pairs were identified (see below). The study was approved by the Mayo Clinic Institutional Review Board, and all patients provided consent for their data to be used for study purposes. Patients with mitral leaflet prolapse and severe MR were offered surgery in accordance with current American College of Cardiology/American Heart Association guidelines. ${ }^{1}$ All patients had preoperative transthoracic echocardiography (TTE), and patients in the robotic group also had electrocardiographically gated volumetric computed tomography $(\mathrm{CT})$ of the chest, abdomen, and pelvis before surgery.

Robotic MV repair is presented as an option in our Cardiology Valvular Heart Disease subspecialty clinics as any other operation would be offered at Mayo Clinic. Cardiologists refer patients to specific modes of therapy on the basis of certain predetermined criteria. In particular, patients with (1) coronary artery disease requiring revascularization, (2) severe peripheral vascular disease precluding safe groin cannulation, or (3) prior median sternotomy or right thoracotomy were not candidates for robotic MV repair in this series. Patients with evidence of more than $50 \%$ diameter stenosis of the coronary lumen on CT underwent cardiac catheterization to confirm the absence of severe coronary disease before robot-assisted MV repair. No additional systematic exclusion criteria were used for the robotic or open group.

\section{Surgical Protocol}

The surgical protocol for the robotic group is as previously described. ${ }^{18}$ After groin and right neck cannulation for bypass, right thoracic access ports were fashioned similar to the method of Siwek and colleagues. ${ }^{15}$ Once the patient was placed on bypass at a flow of $2.4 \mathrm{~L} / \mathrm{min}^{-1} / \mathrm{ms}^{-2}$, a nonabsorbable polypropylene suture (Prolene; Ethicon Inc, Somerville, NJ) with a felt pledget was placed in the ascending aorta just below the right pulmonary artery. A long tack vent cannula (Medtronic, Minneapolis, Minn) was pulled through the chest wall backward, and the needle was then inserted into the cannula. The robotic instruments were used to guide the cannula into the ascending aorta. The transthoracic clamp was inserted through the chest wall, and the heart was arrested with $1 \mathrm{~L}$ of cold blood cardioplegia, which was readministered at 20-minute intervals throughout the crossclamp time. Cardioplegia instillation into the coronary ostia was confirmed using transesophageal echocardiography. In both open and robotic operations, standard published Mayo Clinic open repair techniques were used in all cases. ${ }^{2,19}$ Briefly, full standard triangular resection with 2-layer polypropylene reconstruction was used for posterior leaflet disease (Figure 1, $A, B$ ), and anterior leaflet prolapse was corrected using polytetrafluoroethylene (Gore-Tex; WL Gore \& Associates, Inc, Flagstaff, Ariz) neochord resuspension (Figure 1,D). All repairs were protected using a standard-length posterior annuloplasty band as previously described for all open repairs at the Mayo Clinic (Figure 1, C, E). ${ }^{5}$ Bileaflet repair was performed using a combination of these techniques (Figure 1, F) plus annuloplasty (not shown). Most patients in the robotic group were extubated in the operating room in the second half of the series (and currently) before transfer to the intensive care unit (ICU). Patients were frequently transferred to a stepdown unit by the evening of surgery. After hospital discharge, all patients in the robotic group were seen in follow-up 1 month after surgery. All patients underwent repeated TTE before dismissal from hospital.

\section{Statistical Methods}

Open and robotic groups were propensity matched on the basis of 15 preoperative variables listed in Table 1, including age, gender, New York Heart Association, atrial fibrillation hypertension, hyperlipidemia, diabetes, chronic lung disease, cerebrovascular disease, prior MI, congestive heart failure, and nonsevere coronary artery disease. Charlson index was calculated to further account for comorbidities, including myocardial infarction, congestive heart failure, peripheral vascular disease, cerebrovascular disease, dementia, chronic pulmonary disease, peptic ulcer, mild liver disease, diabetes, diabetes with organ damage, hemiplegia, moderate/severe renal disease, moderate/severe liver disease, metastatic solid tumor, AIDS, rheumatologic disease, and other cancers. Descriptive statistics for categoric variables are reported as frequency and percentage, and continuous variables are reported as mean (standard deviation) or median (range) as appropriate. Continuous variables were compared between the first and second halves of the robotic series by paired $t$ test or Wilcoxon signed-rank test. Categoric variables were compared between robotic and MV open groups using the chi-square test, and continuous variables were analyzed using the 2-sample $t$ test or Wilcoxon rank-sum test where appropriate. The comparisons of baseline variables were reported for both unmatched and matched populations, and the early outcomes between matched robotic and open groups are reported. All statistical tests were 2-sided with the alpha level set at .05 for statistical significance.

\section{RESULTS}

Baseline characteristics of open and robotic groups before and after matching are shown in Table 1. After matching, the 2 groups were similar, including Charlson comorbidity index. Patients were not selected for open or robotic platforms on the basis of leaflet prolapse category, and those with all degrees of prolapse complexity underwent surgery using either approach according to the experience of the surgeon (R.M.S. and H.M.B. performed both robotic and open repair). As shown in Table 2, prolapse categories were similar between open and robotic groups. Standard open repair techniques were used during all mitral repair operations regardless of operative platform. All 


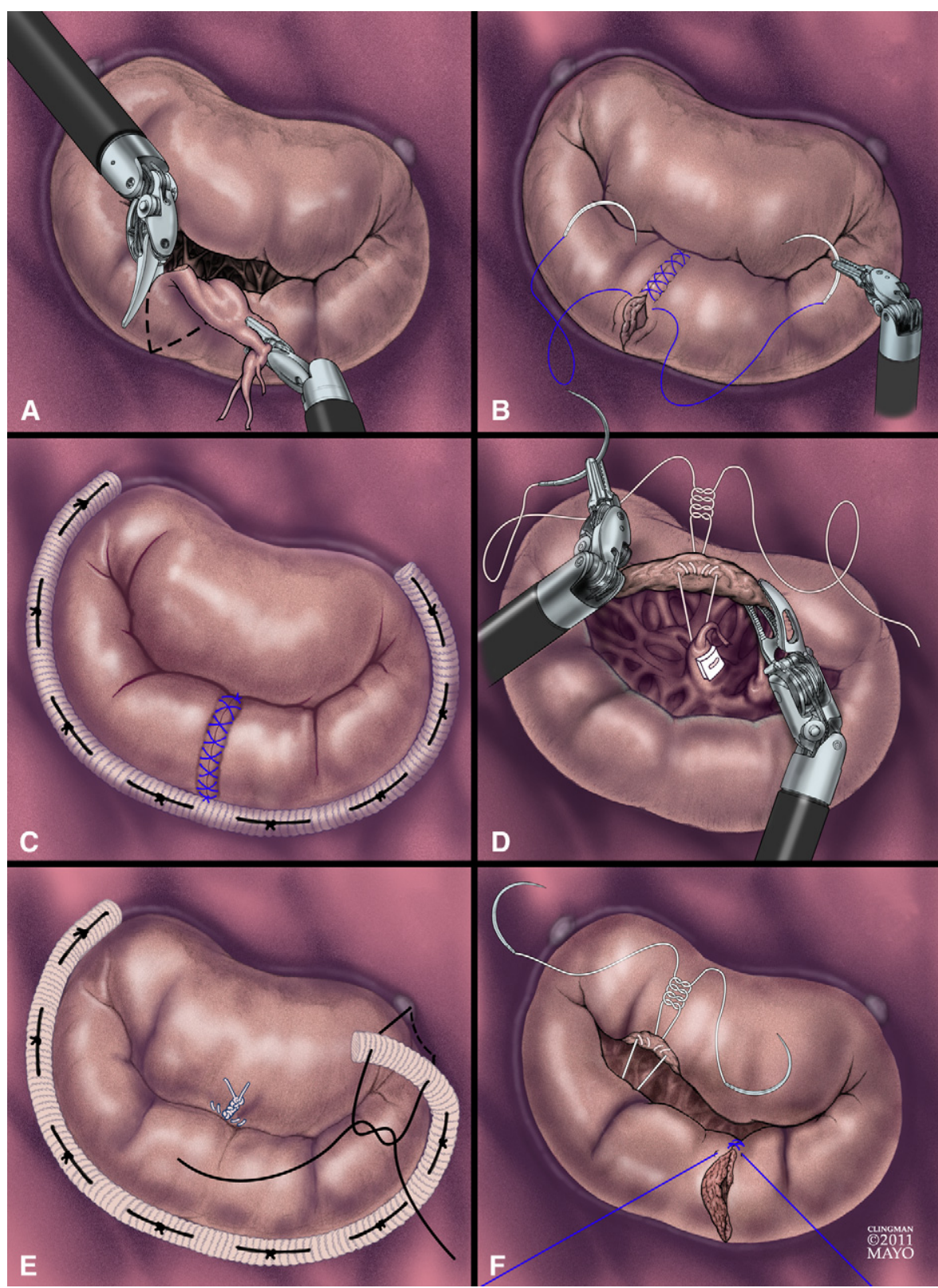

FIGURE 1. Standard Mayo Clinic mitral valve repair techniques using robotic instrumentation. A, The extent of posterior leaflet prolapse is determined and a triangular-shaped resection performed to eliminate redundancy predominating at the leading edge, restoring the position of the coapting margin to the annular plane and decreasing leaflet height. B, The remaining leaflet edges are reapposed using a 2-layer Prolene stitch, restoring normal leaflet coaptation. $\mathrm{C}$, After posterior leaflet correction, a standard-length 63-mm flexible posterior annuloplasty band is inserted using interrupted Ethibond sutures from right to left fibrous trigones. D, Anterior leaflet prolapse is corrected by placing two 5-0 Gore-Tex (WL Gore \& Associates, Inc, Flagstaff, Ariz) neochords between the subtending papillary muscle to the unsupported leaflet edge using a double-armed Gore-Tex pledget-backed mattress stitch. E, After anterior leaflet correction, a 63-mm flexible posterior annuloplasty band is inserted using interrupted Ethibond sutures from right to left fibrous trigones. F, Bileaflet repair is performed using a combination of posterior leaflet resection/reconstruction, anterior leaflet neochord resuspension, and standard-length 63-mm flexible posterior annuloplasty band.

patients in the robotic group underwent complete MV repair consisting of leaflet correction and annuloplasty. There were no conversions to sternotomy in the robotic group.

This study includes patients who underwent operation during the initial phase of our robotic mitral repair program.
Team experience led to improvements of efficiency both in the operation and postoperatively. As shown in Figure 2, significant decreases in median perfusion time, crossclamp time, total ICU stay, postoperative ventilation, and length of hospital stay were noted between the first and second halves 
TABLE 1. Baseline characteristics

\begin{tabular}{|c|c|c|c|c|c|c|c|c|c|c|c|c|c|c|}
\hline \multirow[b]{3}{*}{ Variable } & \multicolumn{6}{|c|}{ Unmatched } & \multirow[b]{3}{*}{$\boldsymbol{P}$} & \multicolumn{6}{|c|}{ Propensity matched } & \multirow[b]{3}{*}{$\boldsymbol{P}$} \\
\hline & \multicolumn{3}{|c|}{ Open $(\mathbf{N}=199)$} & \multicolumn{3}{|c|}{ Robotic $(N=102)$} & & \multicolumn{3}{|c|}{ Open $(\mathrm{N}=95)$} & \multicolumn{3}{|c|}{ Robotic $(\mathbf{N}=95)$} & \\
\hline & Mean & SD & Median & Mean & SD & Median & & Mean & SD & Median & Mean & SD & Median & \\
\hline Age & 59.91 & 14.51 & 61.00 & 54.09 & 11.37 & 54.50 & $<.001$ & 55.69 & 14.09 & 56.00 & 54.88 & 11.04 & 56.00 & .660 \\
\hline BMI & 26.03 & 4.22 & 25.69 & 27.13 & 3.83 & 27.16 & .009 & 26.95 & 4.41 & 26.79 & 26.83 & 3.57 & 27.13 & .839 \\
\hline Creatinine & 0.99 & 0.21 & 1.00 & 0.97 & 0.17 & 1.00 & .594 & 0.95 & 0.16 & 0.90 & 0.97 & 0.17 & 1.00 & .366 \\
\hline \multirow[t]{2}{*}{ Ejection fraction } & 63.91 & 6.78 & 65.00 & 65.73 & 6.69 & 66.00 & .020 & 65.34 & 5.79 & 65.00 & 65.34 & 6.63 & 66.00 & .702 \\
\hline & $\mathrm{N}$ & $\%$ & & $\mathrm{~N}$ & $\%$ & & $P$ & $\mathrm{~N}$ & $\%$ & & $\mathrm{~N}$ & $\%$ & & $P$ \\
\hline Cerebrovascular disease & 13 & 6.53 & & 1 & 0.98 & & .040 & 0 & 0.00 & & 1 & 1.05 & & 1.000 \\
\hline Chronic lung disease & 15 & 7.54 & & 6 & 5.88 & & .594 & 5 & 5.26 & & 6 & 6.32 & & .756 \\
\hline Congestive heart failure & 26 & 13.07 & & 1 & 0.98 & & $<.001$ & 2 & 2.11 & & 1 & 1.05 & & 1.000 \\
\hline Coronary disease & 0 & 0.00 & & 3 & 2.94 & & .038 & 0 & 0.00 & & 3 & 3.16 & & .246 \\
\hline Diabetes & 4 & 2.01 & & 1 & 0.98 & & .665 & 2 & 2.11 & & 1 & 1.05 & & 1.000 \\
\hline Dyslipidemia & 117 & 58.79 & & 56 & 54.90 & & .518 & 49 & 51.58 & & 52 & 54.74 & & .663 \\
\hline Hypertension & 74 & 37.19 & & 34 & 33.33 & & .510 & 29 & 30.53 & & 32 & 33.68 & & .641 \\
\hline Male & 139 & 69.85 & & 78 & 76.47 & & .225 & 76 & 80.00 & & 73 & 76.84 & & .597 \\
\hline Myocardial infarction & 4 & 2.01 & & 0 & 0.00 & & .304 & 2 & 2.11 & & 0 & 0.00 & & .497 \\
\hline NYHA 1 and 2 & 143 & 71.86 & & 92 & 90.20 & & $<.001$ & 86 & 90.53 & & 85 & 89.47 & & .809 \\
\hline Preoperative atrial fibrillation & 21 & 10.55 & & 4 & 3.92 & & .048 & 5 & 5.26 & & 4 & 4.21 & & 1.000 \\
\hline Charlson $=0$ & 103 & 51.76 & & 71 & 69.61 & & .002 & 62 & 65.26 & & 75 & 78.95 & & .109 \\
\hline Charlson $=1$ & 41 & 20.60 & & 20 & 19.61 & & & 20 & 21.05 & & 12 & 12.63 & & \\
\hline Charlson $\geq 2$ & 55 & 27.64 & & 11 & 10.78 & & & 13 & 13.68 & & 8 & 8.42 & & \\
\hline
\end{tabular}

BMI, Body mass index; NYHA, New York Heart Association.

of the robotic series (Appendixes 1-3). Overall, median crossclamp time ( 31 vs 75 minutes, $P<.001$ ) and median perfusion time ( 40 vs 101 minutes, $P<.001$ ) were shorter in the open group compared with the robotic group. Despite this, median length of ventilation (6.4 vs 4 hours, $P<.001)$, median ICU stay (22.5 vs 18.5 hours, $P<.001$ ), and median length of hospital stay (5 vs 3 days, $P<.001$ ) were longer in the open group. During the latter half of the series, all of the following decreased significantly in the robotic group (Figure 2): median crossclamp time ( 85 vs 63 minutes, $P<.001$ ), median perfusion time (122 vs 86 minutes, $P<.001$ ), median length of postoperative ventilation ( 6.4 vs 0 hours, $P<.001$ ), median ICU stay ( 20.5 vs 13.1 hours, $P<.001$ ), and median hospital stay (4 vs 3 days, $P<.001$ ).

Early postoperative surgical outcomes (in hospital plus $\leq$ 30 days) are reported in Table 3 and were strikingly similar between open and robotic groups. The incidence of any Society of Thoracic Surgeons complication was similar $(6 \%$ each, $P=1.00$ ). To compare complications as reported in the recent EVEREST II trial publication, early outcomes were stratified similarly (Table 3). ${ }^{10}$ Finally, there was no difference in the early incidence of temporary postoperative

TABLE 2. Mitral leaflet prolapse subsets

\begin{tabular}{lccc}
\hline Prolapse category $(\mathbf{N})$ & Robotic & Open & $\boldsymbol{P}$ \\
\hline Isolated anterior $(\%)$ & $3(3.2)$ & $3(3.2)$ & 1 \\
Isolated posterior $(\%)$ & $53(57.0)$ & $50(53.8)$ & .66 \\
Bileaflet $(\%)$ & $37(39.8)$ & $40(43.0)$ & .66 \\
\hline
\end{tabular}

atrial fibrillation ( $23 \%$ vs $20 \%, P=.60)$, and none had permanent atrial fibrillation at last follow-up.

The integrity of mitral repair was confirmed in all patients using postbypass transesophageal echocardiography, documenting less than mild residual MR in both open and robotic groups. In addition, residual MR (early efficacy) was indistinguishable between groups by TTE $(P=1.00)$ at dismissal. Patients in the robotic group further underwent protocolized clinical evaluation including TTE at 30 days, and all had less than or equal to mild MR.

\section{COMMENT}

In agreement with prior reports, our study found that the use of simple and standard techniques during surgical correction of degenerative MR led to excellent early postoperative outcomes and low adverse event rates. ${ }^{3,4,6,20-22}$ Novel aspects of this study include (1) the comparison of similar anatomic populations of patients with leaflet prolapse undergoing open or robotic mitral repair using identical technical strategies and (2) propensity matching all categories of degenerative MV disease for preoperative risk factors to account for potential selection bias. We demonstrate that MV repair can be performed via both approaches with very low morbidity and mortality and is effective in correcting severe MR. Robotic repair facilitates a high repair rate, rapid weaning from ventilation, transition to step-down care, and dismissal from hospital. Prior concerns that performance of mitral repair using robotic assistance limits the ability to offer complete anatomic correction of 


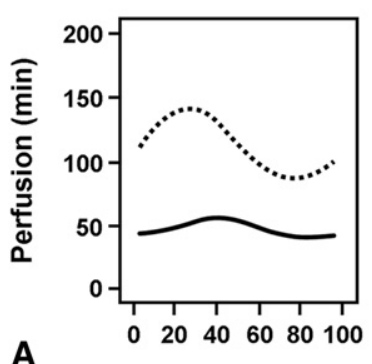

Matched pair (N)

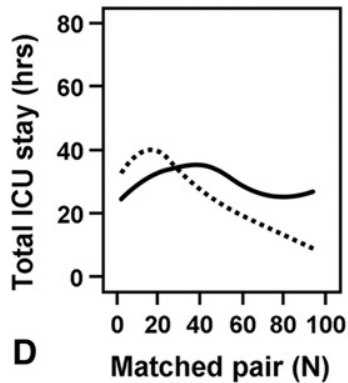

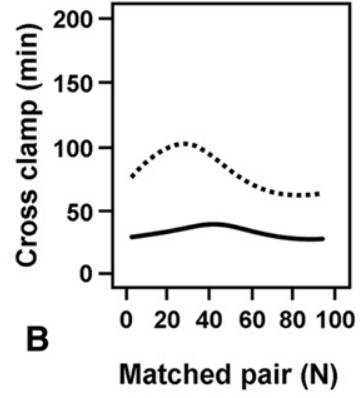

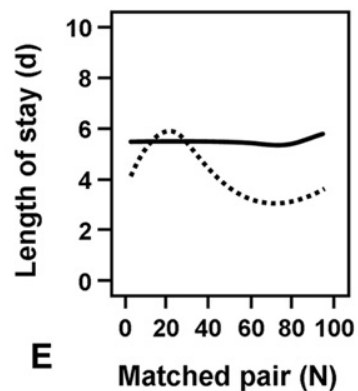

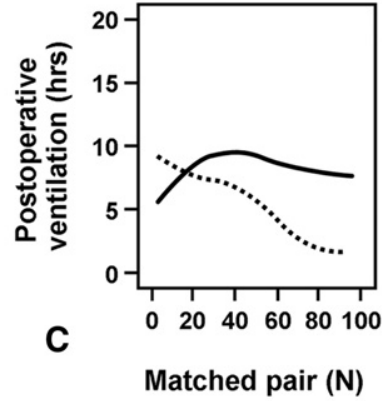

Robotic Open

FIGURE 2. Comparison of operative and early postoperative metrics. (A) Cardiopulmonary bypass and (B) ischemic times were longer for the robotic group overall $(P<.001)$, and both decreased steadily and significantly with time $(P<.001)$. (C) Postoperative duration of ventilation, (D) intensive care unit $(I C U)$ stay, and $(\mathrm{E})$ hospital stay were all shorter in the robotic group $(P<.001)$, also decreasing significantly with time $(P<.001)$.

prolapse or might be associated with increased risk of major adverse events are not supported by the findings of this study.

Guidelines advocating for early repair of degenerative mitral disease associated with severe MR predicate the

TABLE 3. Early postoperative outcomes

\begin{tabular}{|c|c|c|c|c|c|}
\hline & \multicolumn{2}{|c|}{ Open } & \multicolumn{2}{|c|}{ Robotic } & \multirow[b]{2}{*}{$P$} \\
\hline & $\mathbf{N}$ & $\%$ & $\mathbf{N}$ & $\%$ & \\
\hline Any STS complication & 6 & 6.31 & 6 & 6.31 & 1.00 \\
\hline $\begin{array}{l}\text { Any major adverse event } \\
\text { excluding transfusion }\end{array}$ & 5 & 5.26 & 4 & 4.21 & 1.00 \\
\hline $\begin{array}{l}\text { Any major adverse event } \\
\text { including transfusion }\end{array}$ & 23 & 24.21 & 16 & 16.84 & .21 \\
\hline Death & 0 & 0.00 & 0 & 0.00 & NA \\
\hline MI & 0 & 0.00 & 3 & 3.16 & .25 \\
\hline Reoperation failed repair & 1 & 1.05 & 0 & 0.00 & 1.00 \\
\hline Emergent surgery/hemorrhage & 2 & 2.10 & 1 & 1.05 & 1.00 \\
\hline Permanent stroke & 0 & 0.00 & 1 & 1.05 & 1.00 \\
\hline Renal failure & 1 & 1.05 & 0 & 0.00 & 1.00 \\
\hline Deep infection & 0 & 0.00 & 0 & 0.00 & NA \\
\hline Postoperative ventilation $>48 \mathrm{~h}$ & 1 & 1.05 & 1 & 1.05 & 1.00 \\
\hline Surgery GI complication & 1 & 1.05 & 0 & 0.00 & 1.00 \\
\hline Permanent AF & 0 & 0.00 & 0 & 0.00 & NA \\
\hline Septicemia & 0 & 0.00 & 0 & 0.00 & NA \\
\hline Transfusion $\geq 2$ units PRBC & 18 & 18.95 & 10 & 10.53 & .10 \\
\hline \multicolumn{6}{|l|}{ Dismissal mitral regurgitation } \\
\hline None/trivial & 78 & 82.11 & 78 & 82.11 & 1.00 \\
\hline Mild & 16 & 16.84 & 17 & 17.90 & \\
\hline Moderate & 1 & 1.05 & 0 & 0.00 & \\
\hline
\end{tabular}

$A F$, Atrial fibrillation; $G I$, gastrointestinal; $M I$, myocardial infarction; $P R B C$, packed red blood cells; STS, Society of Thoracic Surgeons. performance of such operations on the ability to deliver high repair rates $(>90 \%)$ with low risk of mortality and morbidity. ${ }^{1}$ Benefits of early MV repair in asymptomatic patients without evidence of left ventricular dysfunction include normalization of survival, recovery of left ventricular ejection fraction, restoration of normal ventricular geometry, and regression of left ventricular hypertrophy. ${ }^{23,24}$ Those who advocate for watchful waiting of severe degenerative MR while ventricular size and function deteriorate struggle against a preponderance of evidence warning against such a strategy.

Open sternotomy remains the standard incision for MV repair because the visual and tactile elements of the operation are familiar to all cardiac surgeons, central cannulation is facilitated, and wide exposure affords the opportunity to address concomitant cardiac pathology. Gammie and colleagues ${ }^{25}$ recently detailed the US trends in operative approach during MV operations using the Society of Thoracic Surgeons Adult Cardiac Surgical Database. They found that the incidence of presumed minimally invasive approaches using femoral-femoral cannulation increased from $11.9 \%$ in 2004 to $20.1 \%$ in 2008 ; however, the median number of cases per surgeon was 3 , and only $7.2 \%$ of institutions performed at least 1 mitral operation using robotic assistance. Although crossclamp and perfusion times were longer in the minimally invasive group, MV repair rates were higher $(85 \%$ vs $67 \%, P<.0001)$ and operative mortality was similar. Patients in the minimally invasive group were less likely to undergo blood 
transfusion (odds ratio $=0.86, P<.0001$ ), but stroke risk was greater (odds ratio $=1.96, P<.0001$ ). The authors assert that less-invasive MV operations are technically more demanding and that "the learning curve is significant." The data we present in our current report are largely in agreement with the finding that crossclamp and bypass times are initially longer during minimally invasive operations; however, we demonstrate that they do decrease after successful navigation of technical and team-based learning curves. Moreover, the incidence of major complications is similar to open sternotomy, thus permitting MV repair to remain one of the lowest-risk cardiac surgical procedures tracked by the Society of Thoracic Surgeons Database. $^{25}$

Why is the option of a minimally invasive approach important in modern cardiac surgery? Despite the fact that incomplete anatomic leaflet correction and the absence of an annuloplasty have both been shown to limit repair durability, ${ }^{26,27}$ percutaneous techniques mimicking the edgeto-edge repair are being promoted as equivalent. In the EVEREST II trial, ${ }^{10}$ approximately one quarter of patients who received a MitraClip required immediate surgical rescue in the hospital, and moderate or greater MR developed in approximately $50 \%$ more by 1 year. Many have questioned whether moderate MR is a satisfactory hemodynamic metric, and others have remained puzzled by the combined safety end point classifying stroke, death, and red blood cell transfusion as complications of equal magnitude. Of those who underwent operation after a failed clip, approximately half required mitral replacement, presumably for clip-related trauma precluding rescue repair. Yet, despite serious limitations in effectiveness, the MitraClip has been sought out by those who aim to avoid surgical intervention because of the fear of sternotomy, postoperative disability, or perturbation in quality of life. The question thus becomes not "if" a minimally invasive approach is relevant in degenerative mitral disease but "how" we can reproduce proven results of traditional trans-sternal MV repair through lessinvasive and better-tolerated incisions. ${ }^{8}$ The technical strategies used during MV repair in our series were identical between open and robotic groups, and were performed using standard Mayo Clinic algorithms for complete mitral leaflet repair and standard length posterior annuloplasty support. There was no apparent quality "cost" for the performance of the same operation through less-invasive incisions; because repair rate was $100 \%$, there were no conversions to sternotomy, and mortality was $0 \%$. Moreover, the risk of important major adverse events, such as stroke, death, reoperation for bleeding or other cardiac causes, and MI, were reassuringly low and significantly less than those reported in the recent EVEREST II trial. The notion that minimally invasive surgery is without potential patient benefit or unsafe even when performed by appropriately trained teams is as illogical as the assertion that one technique is superior to the other. Finally, the purpose of MV repair is to free patients from significant MR, and there was gratifying similarity in the early efficacy of both approaches in this regard. Most patients were dismissed from hospital with no to trivial residual regurgitation, consistent with published reports of open and minimally invasive surgical MV repair. ${ }^{8,17,28}$

A recent series detailing the early results of robotic posterior mitral leaflet repair matched to sternotomy and thoracotomy groups ${ }^{17}$ also demonstrated that although bypass and crossclamp times were longer, safety and efficacy were equivalent among groups. Variation in technical aspects of repair performed between platforms was likely to have occurred, as has been reported previously by the Cleveland group. ${ }^{29-31}$ Median crossclamp time for the posterior leaflet robotic repair series was 85 minutes, which is similar to our current report including all leaflet prolapse subsets, 75 minutes overall, and 63 minutes during the latter half of the current series. Our policy of uniform CT screening, direct ascending aortic tack vent insertion, and transthoracic crossclamp placement to diminish the likelihood of difficulties with cannulation, perfusion, or cardiac/neurologic protection may have helped prevent urgent conversion to sternotomy. Hospital stay in our current report was slightly shorter than in prior series, which might relate to differences in institutional postoperative care pathways. Rodriguez and colleagues, ${ }^{13}$ from East Carolina University, published pioneering results of robotic repair for anterior/bileaflet prolapse between 2000 and 2006. The authors used techniques that were different from ours, reporting rates of freedom from MR similar to conventional approaches during a mean follow-up period of 795 days.

Certain important issues remain to be addressed. The increased incidence of stroke in the literature is concerning. ${ }^{25}$ We believe that avoidance of femoral arterial cannulation in the presence of more than mild atherosclerotic burden is prudent. Second, although others have cited the increased complexity of MV repair performed through minimally invasive incisions, we believe that the adoption of standard, simplified, reproducible, and durable techniques in both open and minimally invasive operations are likely to improve efficiency, safety, and durability over time. Third, it is our opinion that the participation of a skilled bedside surgeon in robotic operations is useful because judgmentbased maneuvers, such as tying, retracting, clearing potentially embolic debris, and maintaining a bloodless field, are all skills that evolve with operative experience. Finally, as Chitwood, ${ }^{14}$ Gammie, ${ }^{25}$ and Cheng ${ }^{32}$ have warned, because the learning curve is steep, the a priori facility of a surgeon and team with obtaining high-quality outcomes of MV repair via sternotomy must be ensured before initiation of a robotic repair program. National and international guidelines are currently being drafted addressing these points. 


\section{Limitations}

This is a retrospective observational series and bears traditional limitations. We attempted to control for comorbidities influencing the decision to direct patients into robotic and open repair pathways using propensity matching. Although a randomized study would be ideal, in reality it would be difficult to perform because patients often arrive in our Clinics expecting a specific surgical approach. This is a study examining intraoperative and early postoperative outcomes of contemporary open versus robotic MV repair. A strength is that the techniques and strategies used to obtain complete anatomic correction of prolapse and annular reduction are identical in both open and robotic mitral repair surgeries at Mayo Clinic, which has not been the case in most prior reports to date. The limitations of reporting contemporary results are that mid- and long-term outcomes are not presently available. We are currently accruing and plan to report outcome data as available. It is reassuring that the exact technical maneuvers described and used in this report have been associated with excellent long-term durability and freedom from reoperation as detailed in prior publications. ${ }^{3,21}$ We thus would expect similar results of the same technique using smaller incisions; however, actual echocardiographic and clinical follow-up data will be essential to definitively speak to this point. As anesthetic and pain control algorithms become standardized between cohorts with increasing experience, we will be better poised to study and compare early postoperative outcomes.

\section{CONCLUSIONS}

Contemporary robotic MV leaflet repair plus flexible posterior annuloplasty using standard techniques and small port access incisions allows performance of the same complete correction as open valvuloplasty for all categories of leaflet prolapse with near certainty and very low mortality. Robotic mitral repair is effective in correcting MR and facilitates rapid weaning from ventilation, transition to step-down care, and dismissal from hospital. The incidence of early major adverse events after open and robotic degenerative MV repair are similarly low and less than recently reported in the EVEREST II trial, thereby establishing an appropriate benchmark against which future nonsurgical therapies should be evaluated.

\section{References}

1. Bonow RO, Carabello BA, Chatterjee K, De Leon AC Jr, Faxon DP, Freed MD, et al. ACC/AHA 2006 guidelines for the management of patients with valvular heart disease: a report of the American College of Cardiology/American Heart Association Task Force on Practice Guidelines (Writing Committee to Revise the 1998 Guidelines for the Management of Patients with Valvular Heart Disease): developed in collaboration with the Society of Cardiovascular Anesthesiologists. Circulation. 2006;114(5):e84-231.

2. Suri R, Orszulak T. Triangular resection for repair of mitral regurgitation due to degenerative disease. Operative Techniques Thorac Cardiovasc Surg. 2005;10:194-9.
3. Suri RM, Schaff HV, Dearani JA, Sundt TM 3rd, Daly RC, Mullany CJ, et al. Survival advantage and improved durability of mitral repair for leaflet prolapse subsets in the current era. Ann Thorac Surg. 2006;82:819-26.

4. Braunberger E, Deloche A, Berrebi A, Abdallah F, Celestin JA, Meimoun P, et al. Very long-term results (more than 20 years) of valve repair with Carpentier's techniques in nonrheumatic mitral valve insufficiency. Circulation. 2001;104:I-8-11.

5. Brown ML, Schaff HV, Li Z, Suri RM, Daly RC, Orszulak TA. Results of mitral valve annuloplasty with a standard-sized posterior band: is measuring important? J Thorac Cardiovasc Surg. 2009;138:886-91.

6. Gillinov AM, Cosgrove DM, Blackstone EH, Diaz R, Arnold JH, Lytle BW, et al. Durability of mitral valve repair for degenerative disease. $J$ Thorac Cardiovasc Surg. 1998;116:734-43.

7. Maisano F, Vigano G, Blasio A, Colombo A, Calabrese C, Alfieri O. Surgical isolated edge-to-edge mitral valve repair without annuloplasty: clinical proof of the principle for an endovascular approach. EuroIntervention. 2006;2:181-6.

8. McClure RS, Cohn LH, Wiegerinck E, Couper GS, Aranki SF, Bolman RM III, et al. Early and late outcomes in minimally invasive mitral valve repair: an eleven-year experience in 707 patients. J Thorac Cardiovasc Surg. 2009; 137:70-5.

9. Sharony R, Saunders PC, Nayar A, McAleer E, Galloway AC, Delianides J, et al. Semirigid partial annuloplasty band allows dynamic mitral annular motion and minimizes valvular gradients: an echocardiographic study. Ann Thorac Surg. 2004;77:518-22.

10. Feldman T, Foster E, Glower DG, Kar S, Rinaldi MJ, Fail PS, et al. Percutaneous repair or surgery for mitral regurgitation. $N$ Engl J Med. 2011;364:1395-406.

11. Cohn LH, Adams DH, Couper GS, Bichell DP, Rosborough DM, Sears SP, et al. Minimally invasive cardiac valve surgery improves patient satisfaction while reducing costs of cardiac valve replacement and repair. Ann Surg. 1997;226:421-8.

12. Schmitto JD, Mokashi SA, Cohn LH. Minimally-invasive valve surgery. J Am Coll Cardiol. 2010;56:455-62.

13. Rodriguez E, Nifong LW, Chu MW, Wood W, Vos PW, Chitwood WR, et al. Robotic mitral valve repair for anterior leaflet and bileaflet prolapse. Ann Thorac Surg. 2008;85:438-44.

14. Chitwood WR Jr, Rodriguez E, Chu MWA, Hassan A, Ferguson TB, Vos PW, et al. Robotic mitral valve repairs in 300 patients: a single-center experience. J Thorac Cardiovasc Surg. 2008;136:436-41.

15. Siwek LG, Reynolds B. Totally robotic mitral valve repair. Operative Techniques Thorac Cardiovasc Surg. 2007;12:235-49.

16. Murphy DA, Miller JS, Langford DA, Snyder AB, Murphy DA, Miller JS, et al. Endoscopic robotic mitral valve surgery. J Thorac Cardiovasc Surg. 2006;132:776-81.

17. Mihaljevic T, Jarrett CM, Gillinov AM, Williams SJ, DeVilliers PA, Stewart WJ, et al. Robotic repair of posterior mitral valve prolapse versus conventional approaches: potential realized. J Thorac Cardiovasc Surg. 2011;141:72-80. e1-4.

18. Suri RM, Burkhart HM, Rehfeldt KH, Enriquez-Sarano M, Daly RC, Williamson EE, et al. Robotic mitral valve repair for all categories of leaflet prolapse: improving patient appeal and advancing standard of care. Mayo Clin Proc. $2011 \mathrm{Jul} 14$. [Epub ahead of print.]

19. Schaff HV, Suri RM, Enriquez-Sarano M, Schaff HV, Suri RM, EnriquezSarano M. Indications for surgery in degenerative mitral valve disease. Semin Thorac Cardiovasc Surg. 2007;19:97-102.

20. David TE. Outcomes of mitral valve repair for mitral regurgitation due to degenerative disease. Semin Thorac Cardiovasc Surg. 2007;19:116-20.

21. Mohty D, Orszulak TA, Schaff HV, Avierinos JF, Tajik JA, Enriquez-Sarano M. Very long-term survival and durability of mitral valve repair for mitral valve prolapse. Circulation. 2001;104(Suppl 1):i1-7.

22. De Bonis M, Lorusso R, Lapenna E, Kassem S, De Cicco G, Torracca L, et al. Similar long-term results of mitral valve repair for anterior compared with posterior leaflet prolapse. J Thorac Cardiovasc Surg. 2006;131:364-70.

23. Stulak JM, Suri RM, Dearani JA, Burkhart HM, Sundt TM 3rd, EnriquezSarano M, et al. Does early surgical intervention improve left ventricular mass regression after mitral valve repair for leaflet prolapse? J Thorac Cardiovasc Surg. 2011;141:122-9.

24. Enriquez-Sarano M, Sundt TM III. Early surgery is recommended for mitral regurgitation. Circulation. 2010;121:804-12.

25. Gammie JS, Zhao Y, Peterson ED, O'Brien SM, Rankin JS, Griffith BP. J. Maxwell Chamberlain Memorial Paper for Adult Cardiac Surgery. Less-invasive mitral valve operations: trends and outcomes from the society of thoracic surgeons adult cardiac surgery database. Ann Thorac Surg. 2010;90:1401-8, 1410.e1; discussion, 1408-10.

26. Timek TA, Nielsen SL, Lai DT, Liang D, Daughters GT, Ingels NB Jr, et al. Effect of chronotropy and inotropy on stitch tension in the edge-to-edge mitral repair. Circulation. 2007;116(11 Suppl):I276-81. 
27. Speziale G, Nasso G, Esposito G, Conte M, Greco E, Fattouch K, et al. Results of mitral valve repair for Barlow disease (bileaflet prolapse) via right minithoracotomy versus conventional median sternotomy: a randomized trial. $J$ Thorac Cardiovasc Surg. 2011;142:77-83. Epub 2010 Oct 5.

28. Galloway AC, Schwartz CF, Ribakove GH, Crooke GA, Gogoladze G, Ursomanno P, et al. A decade of minimally invasive mitral repair: long-term outcomes. Ann Thorac Surg. 2009;88:1180-4.

29. Svensson LG, Atik FA, Cosgrove DM, Blackstone EH, Rajeswaran J, Krishnaswamy G, et al. Minimally invasive versus conventional mitral valve surgery: a propensity-matched comparison. J Thorac Cardiovasc Surg. 2010;139: 926-32.e2

30. George KM, Mihaljevic T, Gillinov AM. Triangular resection for posterior mitral prolapse: rationale for a simpler repair. J Heart Valve Dis. 2009;18: 119-21.

31. Mihaljevic T, Jarrett CM, Gillinov AM, Blackstone EH. A novel running annuloplasty suture technique for robotically assisted mitral valve repair. J Thorac Cardiovasc Surg. 2010;139:1343-4.

32. Cheng W, Fontana GP, De Robertis MA, Mirocha J, Czer LS, Kass RM, et al. Is robotic mitral valve repair a reproducible approach? J Thorac Cardiovasc Surg. 2010;139:628-33.

\section{Discussion}

Dr Lawrence Cohn (Boston, Mass). I have no disclosures. Dr Suri, an excellent presentation of a complicated subject emphasizing last year's article from the Cleveland Clinic, which indicates that robotic surgery can be done well in good centers. You presented some provocative results. I am going to ask you a few technical questions, and then I will save my final philosophical question for the end.

There are 2 things I would like to know from a technical point of view. In the article you said all knots are tied by the assistant surgeon at the operating table. I thought the surgeon operating the robot did the knot tying.

Dr Suri. I actually wrote that the knots are tied by the bedside surgeon. If I can somehow further clarify it in the article, I would be happy to do so. But you bring up a good point, Dr Cohn, it is our opinion that a robotic program aiming to duplicate gold standard, proven open repair techniques must use an experienced bedside surgeon. Others have also followed this model, such as Drs Siwek and Chitwood. Some groups have used trained physician assistants, such as Dr Murphy, which has worked well for him. But again, I can clarify that 2 surgeons (my partner, Dr Harold Burkhart, and I) work together in our repair robotic program.

Dr Cohn. Tell us why you used the same size ring for every patient.

Dr Suri. Good question. The mitral repair techniques that I have discussed today have been used for 20 to 30 years at Mayo Clinic. Both the rationale for the adoption of these techniques and the durability of the approaches have been published in prior reports. Drs Schaff and Orszulak were really the pioneers of the single-sized annuloplasty band. They obtained pathologic data showing that in normal patients, the average mitral annular circumference is $10 \mathrm{~cm}$, further observing that the posterior two thirds of the mitral annulus dilated in those with chronic degenerative MR. I understand that a discussion occurred between Drs Schaff and Dorszulak in the operating room lounge one day, at which point they settled on using a $63-\mathrm{mm}$ band anchored between left and right fibrous trigones. It has worked well over the intervening 30 years, proving to be associated with excellent long-term durability and freedom from reoperation. We recently published a 3-dimensional echo confirmation of the anatomic rationale for using a flexible posterior annuloplasty band to correct posterior annular dilation associated with leaflet prolapse where the anterior intertrigonal distance is generally fixed.

Dr Cohn. Next, you talk about the learning curve, which is extremely important. In your experience, how many months did it take you from the start of your robotic program to reduce the learning curve?

Dr Suri. That is an important question. Our opinion is that a surgeon should become facile with open mitral repair techniques, demonstrating high repair rates and low MR recurrence before venturing into the closed chest milieu. After initiation of our robotic program at Mayo Clinic, it seems that we encountered a "learning curve shoulder" at approximately 50 cases. After that, we noted decreases in crossclamp, bypass, and operating room times. We also documented both cost-savings and certain patient benefits associated with improvements in operating room efficiency. Once patients undergoing robotic surgery are extubated on the operating room table, it is impressive how rapidly they proceed through the postoperative period and return to normal activities after dismissal from the hospital.

Dr Cohn. I assume from what you have just said that there are cost-savings, and I am sure you can document that because of the shorter hospital stays.

Dr Suri. That is correct. Those data are currently being drafted for publication and will hopefully find a compassionate editorial ear.

Dr Cohn. One of the things that validated our original series of mini-mitrals, which was a lower mini-sternotomy 14 years ago, was that patients in a blinded fashion were found to recover faster and return to work faster, something that patients really like. Is this true in your series?

Dr Suri. Yes. I have read your publications, and we owe you a tremendous debt for the pioneering work you have done in this field, Dr Cohn. We concur with your opinion that patients return to normal daily activities more rapidly using less-invasive approaches.

Dr Cohn. Final question, and possibly the most important one. Who should perform robotic mitral valve (MV) surgery? As I indicated, you have a superb experience at the Mayo Clinic, which is numbering more than $250 \mathrm{MV}$ repairs a year. But one of the articles you discussed in your presentation by Gammie and colleagues suggested that the majority of the Society of Thoracic Surgeons see 5 to $10 \mathrm{MVs}$ per year.

My personal belief, as is yours, is that you have to really know how to do MV repair before you use this kind of technique, which is excellent but more complicated. Would you like to comment on that?

Dr Suri. This is an important point. It is the topic of debate among members of our societies and is ultimately a question that will need to be resolved in those forums. That said, there are recent publications pointing to an 80 to $100 \mathrm{MV}$ repair-per-year volume prerequisite before a surgeon and surgical team (a) become efficacious in performing reproducible repair for all categories of leaflet prolapse and thus (b) move forward in attempting to duplicate these same repairs via less invasive incisions, particularly via robotic assistance. Guidelines for the adoption of robotic assistance in cardiac surgery are currently being drafted and will be surfacing in the next year or two, addressing these key points.

Dr Cohn. Thank you. 
Dr Thierry Mesana (Ottawa, Ontario, Canada). Nice presentation and great results. I have a question for you regarding the pathology that you find. How many of these bileaflets or even posterior leaflets were really myxoid degeneration, severe Barlow disease?

Dr Suri. Dr Schaff has shown that oftentimes bileaflet disease can be corrected with an annuloplasty band alone. The incidence of Barlow's type myxomatous disease was obviously much higher in our bileaflet group, both open and robotic. We have a particular technical approach we use at Mayo Clinic for these patients, consisting of triangular resection of the posterior leaflet and placement of polytetrafluoroethylene (Gore-Tex; WL Gore \& Associates, Inc, Flagstaff, Ariz) neochords to the anterior leaflet plus standardlength 63-mm flexible posterior annuloplasty band. I think that is what you are getting at?

Dr Mesana. And the fact you were doing this robotically didn't change this technique?

Dr Suri. Correct — every stitch and each annuloplasty band are placed equivalently when comparing open and robotic MV repairs at Mayo Clinic. We do not modify standard open MV repair techniques when tackling even the most complex valves using robotic assistance.

Dr Francis Wells (Cambridge, United Kingdom). My question is not so much about technique, which you seem to have mastered extremely well, but returning to the cost. We do approximately 200 MV repairs a year, or I do, one surgeon, average length of stay 5 days, and doing it open, the cost is well known and acceptable. What is your added cost for using the robot in terms of disposables and primary investment, because surely you have to add that to your overall cost per patient?

Dr Suri. That is something we have been particularly interested in since the initiation of our robotic mitral repair program. The confounder in addressing this question directly is that there has been a concurrent program to decrease overall costs by $20 \%$ during the same period, so there really have been 2 moving targets, an effort to optimize the cost efficiency of robotic repair within the larger context of overall cost reduction within cardiac surgery at Mayo Clinic.

I can tell you that from our preliminary analysis examining propensity-matched open versus robotic MV repair, it appears that from the time of walking in the hospital door to walking out, costs are equivalent. This includes the amortized cost of robotic equipment, disposables, and all other "bucketed" hospital expenses. We are currently performing the final analyses in that study and will be submitting a manuscript in the near future.

Dr Ralph Damiano (St Louis, Mo). Dr Suri, a superb presentation and congratulations on fantastic results. I have 2 quick questions. First, the advantages of the robotic approach over the sternotomy approach were mainly shorter extubation times, lower ventilation times, and shorter length of stay. Is this advantage really just a result of the smaller incision? Do you really need robotic assistance? That is, can you compare it with a cohort, which I think would be more interesting, of patients undergoing a mini-thoracotomy performed with standard instruments? Do you have any data on that?

My second quick question is regarding the patients with bileaflet disease. What percent of these patients actually had a specific procedure done to the anterior leaflet?

Dr Suri. My own view is that we shouldn't be arguing among ourselves regarding incisional approach. The debate is really akin to a long-needle driver Dr Schaff likes to use or a short one that another colleague might use; the robot is a technical instrument to perform the same operation through a different incision. We were recently at Dr Adams' Mitral Conclave in New York; it was a fantastic meeting, and we discussed this topic at length. It struck me, however, that we often argue among ourselves regarding supremacy of one incision over another, when really we might best expend our energy ensuring accurate interpretation of EVEREST II trial data upholding superior outcomes of contemporary surgical MV repair for degenerative disease of clip technology. We should be offering patients the best technical outcome, and, in our view, that is surgical repair. Further, we are not claiming superiority of sternotomy, thoracotomy, or robotic approaches. We suggest that if repair is performed using proven techniques known to be associated with excellent longterm survival and durability, outcomes should be the same even when carried out via smaller incisions to address patient demand.

In regard to how many anterior leaflets were addressed, I can tell you that overall, depending on the cohort, $20 \%$ to $25 \%$ received polytetrafluoroethylene (Gore-Tex) neochords. Now, at our institution, MVs are repaired with slight stylistic differences while still using the same techniques. What do I mean by that, well, commissural prolapse for instance, might be addressed by one surgeon by inserting a neochord, and another might place a commissural placation stitch. So although those subtle distinctions get a little muddy when performing a retrospective analysis, I can say that true anterior leaflet disease is generally corrected with polytetrafluoroethylene (GoreTex) neochords at Mayo Clinic via both open and robotic approaches.

Dr David Adams (New York, NY). If you can clarify, because I do think there is one confounder here. Your bias in the robotic group, it sounds like you had a bias to extubate on the table. I wonder if your anesthetic management was really the same between these 2 groups, because your crossclamp time in the sternotomy group is 30 minutes, which is phenomenal. My guess is part of this length of stay issue may just be your protocol differences between robotics and standard operations.

Congratulations on your outstanding results in robotics. It is showing again that masterly trained people that really put their head to it can learn this stuff.

Dr Suri. We found that after the adoption of a port-access platform, our teams were so motivated by the early successes and seeing patients doing well that they sought to "advance the game," so to speak, by further improving efficiency within the system. Our anesthesiologists were particularly impressive. They took the lead in deciding to place a paravertebral block in robotic cases prior to anesthetic induction, which subsequently facilitated extubation of patients on the operating room table with no or minimal pain. In fact, I remember an academic cardiologist, head of a program at another institution, who emerged from anesthetic and calmly asked for a stethoscope to listen to his newly repaired MV on the operating room table-true story. We have found these adjunctive anesthetic techniques further facilitate rapid de-escalation in acuity of care and expedite the postoperative recovery pathway. We will be writing about these anesthetic adjuncts soon.

So you are correct, Dr Adams, there are currently differential anesthetic protocols being used among robotic and open repair cases. I would like to reiterate a prior statement, however, no one is claiming superiority of one approach over another. We are merely trying to establish a contemporary surgical standard for degenerative MV repair against which less-effective emerging percutaneous therapies might be judged. 
APPENDIX 1. Comparison between open and robotic groups overall

\begin{tabular}{|c|c|c|c|c|c|c|c|c|c|}
\hline \multirow[b]{2}{*}{ Variable } & \multicolumn{4}{|c|}{ Open } & \multicolumn{4}{|c|}{ Robotic } & \multirow[b]{2}{*}{$\boldsymbol{P}$} \\
\hline & $\mathbf{N}$ & Mean & SD & Median & $\mathbf{N}$ & Mean & SD & Median & \\
\hline Perfusion (min) & 95 & 48.22 & 24.55 & 40.00 & 95 & 113.32 & 40.39 & 101.00 & $<.001$ \\
\hline Crossclamp (min) & 95 & 35.94 & 19.66 & 31.00 & 95 & 81.40 & 28.33 & 75.00 & $<.001$ \\
\hline Postoperative ventilation (h) & 95 & 8.13 & 6.25 & 6.40 & 95 & 14.07 & 88.92 & 4.00 & $<.001$ \\
\hline Total ICU stay (h) & 95 & 25.92 & 20.20 & 22.50 & 95 & 31.29 & 107.61 & 18.50 & $<.001$ \\
\hline Length of stay (d) & 95 & 5.34 & 1.67 & 5.00 & 95 & 4.46 & 6.38 & 3.00 & $<.001$ \\
\hline
\end{tabular}

$S D$, Standard deviation; $I C U$, intensive care unit.

APPENDIX 2. Comparison between first and second halves of robotic series

\begin{tabular}{|c|c|c|c|c|c|c|c|c|c|}
\hline \multirow[b]{2}{*}{ Variable } & \multicolumn{4}{|c|}{ Cases 1-47 } & \multicolumn{4}{|c|}{ Cases 48-95 } & \multirow[b]{2}{*}{$\boldsymbol{P}$} \\
\hline & $\mathbf{N}$ & Mean & SD & Median & $\mathbf{N}$ & Mean & SD & Median & \\
\hline Perfusion (min) & 47 & 131.15 & 44.96 & 122.00 & 48 & 95.85 & 25.59 & 86.00 & $<.001$ \\
\hline Crossclamp (min) & 47 & 94.40 & 30.40 & 85.00 & 48 & 68.67 & 19.14 & 63.00 & $<.001$ \\
\hline Postoperative ventilation (h) & 47 & 26.78 & 125.77 & 6.40 & 48 & 1.62 & 3.42 & 0.00 & $<.001$ \\
\hline Total ICU stay (h) & 47 & 50.66 & 151.20 & 20.50 & 48 & 12.33 & 6.68 & 13.10 & $<.001$ \\
\hline Length of stay (d) & 47 & 5.85 & 8.91 & 4.00 & 48 & 3.10 & 0.31 & 3.00 & $<.001$ \\
\hline
\end{tabular}

$S D$, Standard deviation; $I C U$, intensive care unit.

APPENDIX 3. Comparison between robotic and matched open groups during second half of series

\begin{tabular}{|c|c|c|c|c|c|c|c|c|c|}
\hline \multirow[b]{2}{*}{ Variable } & \multicolumn{4}{|c|}{ Open } & \multicolumn{4}{|c|}{ Robotic } & \multirow[b]{2}{*}{$\boldsymbol{P}$} \\
\hline & $\mathbf{N}$ & Mean & SD & Median & $\mathbf{N}$ & Mean & SD & Median & \\
\hline Perfusion (min) & 48 & 43.27 & 18.27 & 37.00 & 48 & 95.85 & 25.59 & 86.00 & $<.001$ \\
\hline Crossclamp (min) & 48 & 31.83 & 14.85 & 26.50 & 48 & 68.67 & 19.14 & 63.00 & $<.001$ \\
\hline Postoperative ventilation (h) & 48 & 7.43 & 3.56 & 6.30 & 48 & 1.62 & 3.42 & 0.00 & $<.001$ \\
\hline Total ICU stay (h) & 48 & 23.09 & 6.34 & 22.75 & 48 & 12.33 & 6.68 & 13.10 & $<.001$ \\
\hline Length of stay (d) & 48 & 5.29 & 1.43 & 5.00 & 48 & 3.10 & 0.31 & 3.00 & $<.001$ \\
\hline
\end{tabular}

